\title{
Charity launches not-for-profit drug industry
}

Declan Butler, Paris

The Paris-based charity Médecins Sans Frontières (MSF) has launched plans for an ambitious international effort to research, develop and produce drugs for neglected diseases that afflict people in poor countries.

The Drugs for Neglected Diseases Initiative (DNDI) will do "nothing short of creating a global, not-for-profit pharmaceutical industry", says Philippe Kourilsky, director-general of the Institut Pasteur in Paris.

The initiative is being undertaken because the charity - known in the United States as Doctors without Borders - is finding its efforts to deliver medical care increasingly hampered by expensive, ineffective or unavailable drugs, MSF officials say.

The DNDI was formally launched in New York last month, at a meeting attended by 400 public-health experts, among them Harold Varmus, the former director of the US National Institutes of Health (NIH), and Jean-Pierre Garnier, chief executive of the multinational drug company GlaxoSmithKline. The project is being initially backed by the Pasteur, Brazil's Oswaldo Cruz Institute, the Indian Council of Medical Research, the Science University of Malaysia and the World Health Organization.

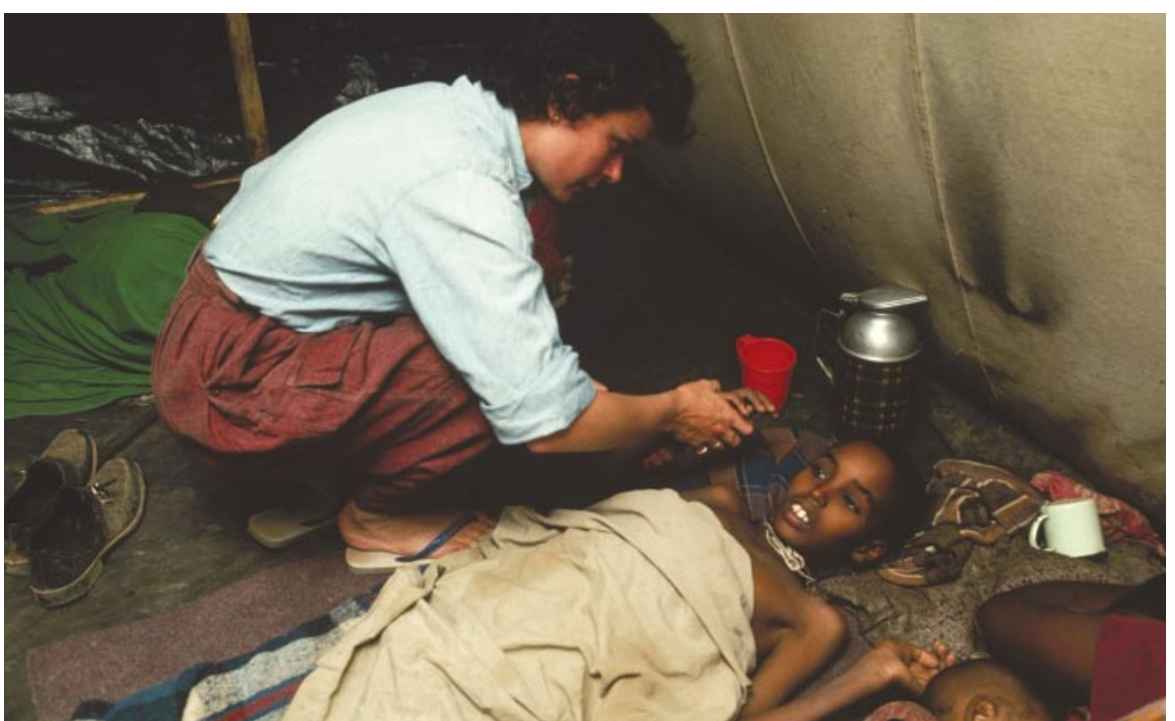

Overcoming neglect: workers in developing countries complain of a lack of available treatments.

MSF, which won the 1999 Nobel peace prize for its worldwide public-health efforts, has put up an initial \$1 million for five pilot projects to develop and produce drugs for the parasitic diseases visceral leishmaniasis and sleeping sickness. And the DNDI will conduct a one-year study to determine the shape

\section{Putin reads science the riot act}

\section{Bryon MacWilliams, Moscow}

Russian Federation president Vladimir Putin has issued an unusually blunt assessment of the state of Russian science and pledged that government funding will be swiftly redirected to the most commercially viable disciplines.

"Today, governmental support of science is completely ineffective," Putin told a rare meeting of the most senior officials in the government and its scientific advisers at the Kremlin on 20 March.

"Everyone is claiming to be on the path of innovation - but almost nothing has been done in real terms," Putin said, adding that Russian science was poorly adapted to the market and over-dependent on government funds. "The business sector cannot find a common language with science," he said.

Putin pledged, nonetheless, to put more government money into research and development. But much of it will be directed at technology development, rather than basic research. "This is the first step towards a sensible, self-regulated departure from the senseless scattering of resources" of the past, he said.

Government officials at the meeting said

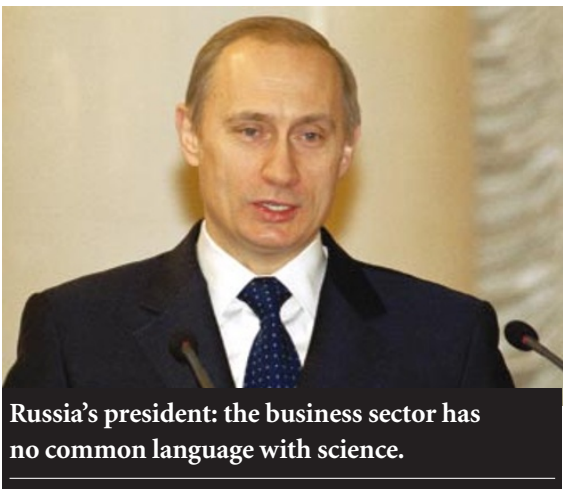

that, under a reform plan to be fully implemented by 2010, the existing network of scientific institutes will be pruned, and resources sent instead to areas regarded as critical to Russia's interests. They claimed that funding would be increased by a factor of five in areas including telecommunications, electronics, aviation, new materials and chemistry.

The president also pledged to raise salaries for young scientists. Although observers are sceptical of his ability to deliver on this and other aspects of the reform plan, scientific leaders welcomed his participation at the conference. of the larger initiative. "This will hammer out realistically what we can and cannot do," says Kourilsky. More funding will then be sought from foundations and governments $-\$ 50$ million annually may be sufficient, says Dyann Wirth, a tropics expert at Harvard School of Public Health.

Established drug companies don't develop drugs for diseases with poor commercial prospects, says Bernard Pecoul, a Geneva-based MSF official - hence the need for the DNDI. He says the initiative's goal is to create a virtual industry driven by "public need" rather than share price.

Wirth says that the idea is not to start up an integrated operation from scratch, but instead to coordinate an international network of researchers, institutions and drug manufacturers. Existing drug companies in developing countries such as India and Brazil will probably have a major role, Wirth adds.

Just as MSF has mobilized doctors worldwide, Pecoul is keen to "mobilize" the research community worldwide. "If we hear of interesting academic work, the network will put them in touch with others to take projects forward," he says.

Big drug companies, which previously clashed with MSF over its efforts to supply low-cost AIDS drugs to Africa, are welcoming the initiative, at least in public. Garnier pledged his support at the New York meeting. Industry has been "very open", says Pecoul, although contributions such as access to molecular-data libraries and the lifting of patent rights will be on a case-by-case basis.

Gerald Keusch, director of NIH's Fogarty International Center, describes the project as "hugely ambitious". But he suggests that the time might be ripe for such an undertaking, and says the Fogarty centre is in discussions with MSF about becoming involved. 